\title{
Presumed congenital infection by Zika virus: findings on psychomotor development - a case report
}

\author{
Ana Carla Gomes Botelho 1 \\ Luana Valeriano Neri 2 \\ Marina Queiroz Ferreira da Silva 3 \\ Thaisa Teixeira de Lima 4 \\ Karla Gonçalves dos Santos 5 \\ Raysa Mayara Araújo da Cunha 6 \\ Alessandra Carolina de Santana Chagas 7 \\ Nauane de Oliveira Lima 8 \\ Ariádne Dias Maux Gonçalves 9 \\ Marcela Raquel de Oliveira Lima 10
}

1-10 Instituto de Medicina Integral Prof. Fernando Figueira (IMIP). Rua dos Coelhos, 300. Recife, PE, Brasil. CEP: 50.070-550. E-mail: marcelaraquelol@gmail.com

\begin{abstract}
Introduction: the identification of Zika virus (ZikV) in the amniotic fluid, in the placenta and in newborns' brains suggests a neurotropism of this agent in the brain development, resulting in neuro-psycho-motor alterations. Thus, this present study reports the assessment of children diagnosed by a congenital infection, presumably by ZikV, followed-up at the Rehabilitation Center Prof. Ruy Neves Baptist at the Instituto de Medicina Integral Prof. Fernando Figueira (IMIP).

Description: as proposed by the Ministry of Health, the following instruments were used to evaluate the neuro-motor functions of four children with microcephaly aged between three and four months: The Test of Infant Motor Performance (TIMP); the functional vision assessment; the manual function scale development; and the clinical evaluation protocol on pediatric dysphagia (PAD-PED).

Discussion: the children evaluated presented atypical motor performance, muscle tone and spontaneous motricity which encompass the symmetry and the motion range of the upper and lower limbs proven to be altered. The functional vision showed alterations which can cause limitations in the performance of functional activities and the learning process. Regarding to the speech articulator's functions observed that the maturation and coordination of sucking, swallowing and breathing did not yet encounter the appropriate age maturity level.
\end{abstract}

Key words Child development, Zika virus, Microcephaly 


\section{Introduction}

After the outbreak of Zika virus (ZikV) in Brazil, there was an increase of 20 times of the annual number registered on microcephaly cases. ${ }^{1}$ The identification of the virus in the amniotic fluid, in the placenta and in the newborns' brains, in addition to the pregnant women's infection symptoms, strongly indicate that $\mathrm{ZikV}$ presents a neurotropism in the brain development, resulting in alterations in the psychomotor development (DNPM) of children who are born with this infection. ${ }^{2-4}$

This unusual event made the Ministry of Health declare, "A Public Health Emergency" in November, 2015 (Decree number 1,813/GM/MS, November 11, 2015) and launched guidelines in forms of protocols on criteria notifying and explaining how to manage these cases. 4

It was recommended an evaluation of this population in a standardized manner in order to meet the clinical findings in the development, directing a previous stimulation in order to attend the specificities of these children, preferably at the beginning of life, a critical period to reduce the commitment level of the DNPM caused by malformation. 5

Thus, this present study reports the evaluation of children diagnosed with a congenital infection presumed to be by $\mathrm{ZikV}$, with the use of standardized instruments in the fields of physical therapy, occupational therapy and speech therapy.

\section{Description}

\section{Evaluation tools}

The instruments used was proposed by the Ministry of Health to assess the neuromotor functions of four infants with microcephaly and other lesions in the Central Nervous System alleged by the congenital infection of ZikV. 5 This report was approved by the Ethics Committee in Research under the number of CAAE 56853916.1.0000.5201 and those responsible for the children agreed to participate in the study and signed an informed consent term, according to the Resolution number 466/2012 of the National Health Council.

The Test of Infant Motor Performance (TIMP) detects alterations in the motor performance of the children from birth to 34 weeks corrected up to 4 months. It is divided into subscales: Observational items - point out the presence of spontaneous movements of the head, arms, legs and trunk - and the elicitation items point out postured responses when the child is placed in the sitting position in prone, supine, lateral and standing. The children's performance in this study was expressed by the final gross R-Score (sum of the points) and the cut-off point of Z-score $<-0.5$ (standard deviations) to diagnose atypical performance. 6

The manual function development scale evaluates the ability of the baby as to his/her development of gripping and follows determined motor patterns according to age: Handling reflex; Reaching in the dorsal decubitus position; Grasping when the hand holds an active object by gripping the ulna palmar. ${ }^{5}$ The functional vision assessment describes the steps of visual development from bright stimuli and objects. Visual behavior was analyzed which should be present by age range: Searching for bright source, visual fixation, eye contact, tracing horizontal and vertical visual, binocular coordination, social smile, development of accommodation and convergence, observation of the hands and reaching for the viewed object. 5

The clinical evaluation protocol on pediatric dysphagia (PAD-PED) is intended to provide information about the bio-dynamics and the development of swallowing, the performance of the child and the clinical diagnosis on dysphagia. Considering the development stages of the stomatognathic system to characterize the suggestive clinical signs for penetration/laryngotracheal aspiration and to assess the dysphagia impact in feeding. This instrument is able to identify normal swallowing and classify oropharyngeal dysphagia as mild, moderate to severe or severe. 7

\section{Case report}

Four babies up to four months of life were evaluated and accompanied by a physician in rehabilitation center at the Instituto de Medicina Integral Prof. Fernando Figueira (IMIP). These cases presented negative test results for other congenital infections that cause microcephaly (toxoplasmosis, cytomegalovirus, rubella, syphilis and HIV) and their mothers presented symptoms consistent of $\mathrm{ZikV}$ infection during the first or second trimester of pregnancy (Tables 1 and 2).

Case 1: Female infant, chronological age (CA) four (4) months. At birth the gestational age (GA) was 38 weeks, birth weight (BW): $3,145 \mathrm{~g}$, head circumference $(\mathrm{HC})-32 \mathrm{~cm}$ and Apgar score at the first and fifth minute of 8 and 9 , respectively. A computerized tomography (CT) was performed and revealed calcifications in the cortico-subcortical splice, corticosubcortical atrophy in the frontal lobe, ventricu- 
lomegaly and cerebellar hypoplasia.

\section{Evaluation of the psychomotor development}

- Motor development: hyperreflexia is mainly in Moro reflections and in asymmetric cervical tonic (RTCA); hypertonia in the four limbs; delays in the motor acquisition; alteration in the spontaneous motricity with absence of symmetry; hands did not reach the mid line; reduction in active motion range (ADM) of the upper limbs (MMSS) and the lower limbs (MMII). Classified as inadequate.

- TIMP: R-score $=91$ and Z-Score $=$ less 1.8 resulting in atypical motor performance.

- Evaluation of the functional vision: positive response for all items related to age since birth until the second month, except for the initiation of the social smile. Items related to the third and fourth month showed a negative response to the "beginning of the observation of the hands" and "can take the hand to the object and grab it."

- PAD-PED: there was a way to breastfeed and bottle feed. The first option, the child holds good lip sealing and good grip (the baby's mouth wide open and lips out holding firmly the nipple and part of the areola) and appropriate frequency/coordination of sucking, swallowing and breathing (SxDxR). As for the bottle, a common artificial teat is used, there is a high extra-oral escape and inadequate gripping, absence of search reflex, intraoral pressure reduced and inappropriate sucking pattern when evaluated the non-nutritive sucking. Classified with mild oropharyngeal dysphagia.

Case 2: Female infant, CA - 3 months, GA - 38 weeks, BW - 1,950g, $\mathrm{HC}$ at birth - $26 \mathrm{~cm}$, Apgar scores at the first and fifth minute of 8 and 9 , respectively. In CT was found: calcifications in corticosubcortical splice, ventriculomegaly, corticosubcortical atrophy and lissencephaly.

\section{Evaluation of the psychomotor development}

- Motor development: hyperreflexia (Moro reflex and RTCA); hypertonia in the four limbs with predominance on the MMSS, muscle spasms, delay in motor acquisition, alteration in spontaneous motricity with considerable reduction of spontaneous movements of the MMSS, hands do not initiate the reach of the mid line, reduce of ADM of the MMSS.

- TIMP: R-Score $=60$ and Z-Score: less 2.4, meaning atypical motor performance.

- Evaluation of the functional vision: showed positive response only at the first test "Looking for the bright source", which should be present since birth, therefore, revealed a deficit on the important functional visual development.

- PAD-PED: presented inadequate lip sealing of the artificial teat, and extra-oral escape, inadequacy in relation to the frequency of SxDxR, absence of the looking for reflex, intraoral pressure reduced and choking during feeding. Demonstrated inadequate sucking pattern. Classified with mild oropharyngeal dysphagia.

Case 3: Male infant, CA: 4 months, GA: 38 weeks, BW: $2,740 \mathrm{~g}, \mathrm{HC}$ at birth: $27.5 \mathrm{~cm}$ and Apgar scores at the first and fifth minute: 9 and 10, respectively. In the CT there were signs of calcification in the periventricular region and in the cortico-subcortical splice and presented ventriculomegaly.

\section{Evaluation of the psychomotor development}

- Motor development: hypertonia in the four limbs and trunk, delay in the motor acquisition and in spontaneous motricity as absence of acquisition and body maintenance in the mid line.

- TIMP: R-Score $=68$ and Z-score less 3.25, characterizing as atypical motor performance.

- Evaluation of the functional vision: positive response for all the items related to age since birth until the second month, except for the initiation of the social smile. For items related to the third and fourth month the response was negative for the "beginning of the observation of hands" and "can take hand to the object and grab it."

- PAD-PED: breastfeeding and bottle-feeding with a common artificial teat, both present parameters of normality and without clinical signs of dysphagia. Classified with normal swallowing.

Case 4: Female infant, CA - 4 months, GA - 38 and 5 days weeks, BW $-2,800 \mathrm{~g}, \mathrm{HC}$ at birth $-29 \mathrm{~cm}$, Apgar scores at the first and fifth minute of 8 and 9, respectively. CT revealed ventriculomegaly, cerebellar hypoplasia, pachygyria and calcifications in the periventricular at the junction cortico-subcortical in the basal ganglia and thalamus.

\section{Evaluation of the psychomotor development}

- Motor development: hyperreflexia (Moro reflex, a labyrinthine tonic reflex and RTCA), hypertonia in the four limbs, muscle spasms, delay in motor acquisition, alterations in the spontaneous motricity with absence of symmetry and hands do not reach the mid line.

- TIMP: R-Score $=74$ and Z-score less 2.8 , classified with atypical motor performance.

- Evaluation of the functional vision: positive 
response only in the first two items related to birth "Searching for bright source" and "present visual fixation - brief", demonstrating a considerable deficit in the functional vision development.

- PAD-PED: Feeding is exclusive by a bottle with a thick liquid and orthodontic artificial teat. Presents extra-oral escape, inadequate lip sealing of the artificial teat, uncoordinated in SxDxR, performs cervical hypertension at the moment of breathing and increased oral transit time. Classified with moderate to severe oropharyngeal dysphagia.

\section{Discussion}

This study presents the results of the interdisciplinary assessment with standardized instruments to detect alterations in the development of infants up to 4 months old with congenital infection presumed to be $\mathrm{ZikV}$. According to the evaluation, these children have in common, hyperreflexia and hypertonia, atypical development and a deficit in the manual function. However, the visual and swallowing function do not follow the same pattern perhaps it is associated to alterations of the brain and the location of the calcifications. After birth, even at the first quarter of life, it is already possible to identify signs of severe brain injuries, from abnormalities present in the muscle tone, in the primitive reflexes, in postural reactions and voluntary motricity.4,7

Urzenia et al. 8 observed a direct correlation between muscle tone and primitive reflexes and an inverse correlation between muscle tone and postural reactions. Hyperreflexia of the RTCA is indicative of the delay in the maturation of the nervous system. Its persistence will prevent the movement of the head to the opposite side making the coordination acquisition of primary sensory-motor such as, the eye-head, auditory-head and hand-hand.?

The persistence of Moro Reflex prevents the development of the body scheme, the appearance of the cervical Reaction of the body rectification and the labyrinth Reaction of the rectification, the Reaction of protective extension of the limbs and the Reaction of balance and volunteer gripping. ${ }^{7}$ It is possible that the hyperreflexia in evaluated cases may have contributed to the deficit in the functionality of the MMSS, in the absence of acquisition and maintaining the body in the mid line, reducing the motricity and the motor performance.

The vision development depends on the integrity of the ocular structures and cortical areas and subcortical. 4 The study performed with children with congenital infection presumed to be $\mathrm{ZikV}$ reveals no sequels including ophthalmic lesions bilateral macular and perimacular, chorioretinal atrophy, as well as abnormalities of the optic nerve. 9 The findings in the CT indicate lesions to the responsible structures by the analysis and the interpretation of the information captured by the eyes, such as thalamus, cerebellum and the cortico-subcortical region. These data reinforce the results of the functional vision assessment testing that the losses identified in the study may bring restrictions on the acquisition of functional activities and the learning

\section{Table 1}

Characterization of individual samples (child and mother) with microcephaly, congenital infection by Zika virus. IMIP, Pernambuco, 2016.

\begin{tabular}{|c|c|c|c|c|c|c|}
\hline \multirow[b]{2}{*}{$\mathbf{N}$} & \multicolumn{6}{|c|}{ Characteristics of child at birth } \\
\hline & Gender & GA (week) & BW (g) & $\mathrm{HC}(\mathrm{cm})$ & $\begin{array}{l}\text { APGAR scores } \\
\text { (1st } \mathrm{min})\end{array}$ & $\begin{array}{c}\text { APGAR scores } \\
\left(5^{\text {th }} \mathrm{min}\right)\end{array}$ \\
\hline 1 & Female & 38 & 3145 & 32.0 & 8 & 9 \\
\hline 2 & Female & 38 & 1950 & 26.0 & 8 & 9 \\
\hline 3 & Male & 36 & 2740 & 27.5 & 9 & 10 \\
\hline \multirow[t]{2}{*}{4} & Female & 38 & 2800 & 29.0 & 8 & 9 \\
\hline & \multicolumn{6}{|c|}{ Maternal characteristics } \\
\hline & Age(years) & \multicolumn{2}{|c|}{ Origin } & \multicolumn{3}{|c|}{ ZikV Symptoms during pregnancy } \\
\hline 1 & 26 & \multicolumn{2}{|c|}{ City } & \multicolumn{3}{|c|}{ Fever, Rash, Pruritus Arthralgia, Exanthema } \\
\hline 2 & 17 & \multicolumn{2}{|c|}{ Rural } & \multicolumn{3}{|c|}{ Fever, Rash, Pruritus Arthralgia, Exanthema } \\
\hline 3 & 24 & \multicolumn{2}{|c|}{ Rural } & \multicolumn{3}{|c|}{ Rash, Exanthema, Pruritus } \\
\hline 4 & 27 & \multicolumn{2}{|c|}{ City } & \multicolumn{3}{|c|}{ Rash, Exanthema, Pruritus } \\
\hline
\end{tabular}


Results of the computerized tomography of the brain, clinical findings and results of the standardized assessments of Microcephaly cases due to congenital infection by Zika virus. IMIP, Pernambuco, 2016.

Computerized tomography of the brain without contrast

Clinical findings

Results of standardized assessments

Location of calcifications

\begin{tabular}{lllllllllll} 
& JCS & $\begin{array}{c}\text { Periven- } \\
\text { tricular }\end{array}$ & $\begin{array}{c}\text { Frontal } \\
\text { lobe }\end{array}$ & $\begin{array}{c}\text { Parietal } \\
\text { lobe }\end{array}$ & $\begin{array}{c}\text { Basal } \\
\text { ganglia }\end{array}$ & Thalamus & ACS & VMG & HC & MDC \\
\hline 1 & Yes & No & Yes & No & No & No & Yes & Yes & Yes & No
\end{tabular}

No

No

No

No

Yes Yes

No

Yes

Hypertonia

Hyperreflexi

Irritability

3

Yes

Yes

No

No

No

No

No Yes

No

No

Hypertonia

Hyperreflexia

Muscle spasms

No

No

No

Yes

Yes

No Yes

Yes

Yes

Irritability

Hyperreflexia

Hyperreflexia

Atypical Deficit Deficit Moderate

to severe

Dysphagia

$\mathrm{N}=$ number of cases; JCS = cortico-subcortical splice; $\mathrm{ACS}=$ cortico-subcortical atrophy; VMG = Ventriculomegaly; $\mathrm{HC}=$ cerebellar hypoplasia; $\mathrm{MDC}=$ malformation of the cortical development; TIMP = Test of Infant Motor Performance; DM = motor performance; PAD - PED = protocol of clinical evaluation on pediatric dysphagia. 
process. Despite of this, the absence of the visualmotor evidence observed in cases 1 and 3, do not necessarily mean delay in the functional vision development since the motor commitment of the children may have influenced this evidence, as it needs the active movements of the upper limbs.

The findings related to the aspects of speech reveal immaturity and consequently, the lack of the functions of sucking, swallowing and breathing were unsuitable for the age. Although it is impossible to conclude that this is a pattern of delay, the characteristics of lesions in various structures connect to the center of swallowing, as the cerebellum, basal ganglia, thalamus and cortico-subcortical region reveals a possibility of raising the degree of dysphagia, which occurred specifically in case 4 . Although lesions in the structures are part of a system that regulates factors such as sensitivity, force of contraction of the muscles and in sequence of movements can lead to involuntary movements or inaccurate speech articulator of the organs with a probability of extra-oral escape or later have difficulties in training and propel food bolus with time increased to swallowing, as observed in the cases evaluated. 10

The results found an inadequacy of oral sensorymotor system, as evidenced by the immaturity of SxDxR which can bring losses in the following stages, such as: transition from food consistency, the use of a glass, spoon and chewing. 10

This present study highlights in providing initial information about the possible deficits in this population, aiming to help the rehabilitation team in early intervention and therefore, minimize the functional limitations in the future. The prediction of the development at an early age in an emerging pathology found in this study requires as a necessity, however it is a bit challenging. The achievement of other researches with a longitudinal design in monitoring the development in this population is crucial to have a better understanding of this problem.

\section{References}

1 Schuler-Faccini L, Ribeiro EM, Feitosa IM, Horovitz DD, Cavalcanti DP, Pessoa A, Doriqui MJ, Neri JI, Neto JM, Wanderley HY, Cernach M, El-Husny AS, Pone MV, Serao CL, Sanseverino MT.Possible Association between Zika Virus Infection and Microcephaly - Brazil, 2015. MMWR Morb Mortal Wkly Rep. 2016; 65: 59-62.

2. Mlakar J, Korva M, Tul N, Popovic M, Poljsak-Prijatelj M, Mraz J, Kolenc M, RusKR, Vipotnik TV, Vodušek VF, Vizjak A, Pižem J, Petrovec M, Županc TA. Zika virus associated with microcephaly. N Engl J Med. 2016; 374 : 951-8

3. Tang H, Hammack C, Ogden SC, Wen Z, Qian X, Li Y. Zika virus infects human cortical neural progenitors and attenuates their growth. Cell Stem Cell 2016; 18 (5): 587-90.

4. Brasil. Ministério da Saúde. Secretaria de Atenção à Saúde. Protocolo de atenção à saúde e resposta à ocorrência de microcefalia relacionada à infecção pelo vírus Zika Ministério da Saúde, Secretaria de Atenção à Saúde Brasília, DF; 2015. 49p. [acesso em 5 abr 2016]. Disponível em: http://portalsaude.saude.gov.br/images/PROTOCOLO\%20DE\%20ATENDIMENTO\%20PARA\%20MICR OCEFALIA.pdf.

5. Brasil, Ministério da Saúde. Secretaria de Atenção à Saúde. Diretrizes de estimulação precoce: crianças de zero a 3 anos com atraso no desenvolvimento neuropsicomotor decorrente de microcefalia. O Ministério, Brasília: Ministério da Saúde, 2016. 123p. Disponível em: http://www.saude
go.gov.br/public/media/ZgUINSpZiwmbr3/200669220000 62091226.pdf. Acesso em 16/05/2016.

6. Campbell SK. The Test of Infant Motor Performance. Test User's Manual. Version 2.0.Chicago, IL: Infant Motor Performance Scales, LLC; 2005.

7. Almeida FC, Bühler KEB, Limongi SC. Protocolo de avaliação clínica da disfagia pediátrica (PAD-PED). Barueri: Pró-Fono; 2014.

8. Bobath B, Bobath KA. Diferenciação entre padrões priitivos e anormais. In: Bobath B. Desenvolvimento motor nos diferentes tipos de paralisia cerebral. São Paulo: Manoel; 1990. p. 19-22.

9. Urzêda RN, Oliveira TG, Campos AM, Formiga CK. Reflexos, reações e tônus muscular de bebês pré-termo em um programa de intervenção precoce. Rev Neurocienc 2009; 17(4): 319-25.

10. Ventura CV, Maia M, Ventura BV, Linden VVD, Araújo EB, Ramos RC, Eveline B. Araújo EB, Regina C. Ramos RC, Rocha MA, Carvalho MD, Belfort R, Ventura LO. Ophthalmological findings in infants with microcephaly and presumable intra-uterus Zika virus infection. Arq Bras Oftalmol. 2016; 79 (1): 1-3.

Received on June 22, 2016

Final version presented on September 6, 2016

Approved on September 27, 2016 